\title{
Endovascular Treatment of Cerebral Aneurysms Not Presented by Classic Subarachnoid Hemorrhage (First Year Experience by Neurologist) \\ Eman M Khedra $^{a}$, Ahmed Bassiony ${ }^{\mathrm{b}}$, Hany Zaky-Eldin ${ }^{\mathrm{b}}$, Bastawy Fawal ${ }^{\mathrm{c}}$, Ahmed Shoyb ${ }^{\mathrm{c}}$ \\ ${ }^{a}$ Department of Neuropsychiatry, Faculty of Medicine, Assiut University, Assuit, Egypt and the Academic Director of Neuropsychiatry Department, Faculty of Medicine, Aswan University, Aswan, \\ ${ }^{\mathbf{b}}$ Department of Neuropsychiatry, Faculty of Medicine, Ain shams University, Cairo, ${ }^{\mathbf{c}}$ Department of Neuropsychiatry, Faculty of Medicine, Aswan University, Aswan, Egypt corresponding author: Ahmed Shoyb ,email: ahmed.shoyb@yahoo.com
}

\begin{abstract} angiographically before procedure and 3-6 months after procedure therapy with less morbidity and mortality rates.

Keywords: subarachnoid hemorrhage, rupture aneurysm, coiling,

Ethical approval no: ASU 44-1-16.

\section{INTRODUCTION}

The prevalence of intracranial aneurysms are about 1 to 5 percent in adult population. Often they will stay asymptomatic during the course of life ${ }^{(1)}$. Rupture of an intracranial aneurysm is the most serious complication that lead to aneurismal subarachnoid hemorrhage (ASAH), which accounts for $5 \%$ to $10 \%$ of all strokes. ASAH causes more morbidity and mortality than other stroke types ${ }^{(2)}$. Most unruptured intracranial aneurysms (UIAs) are detected incidentally and increasingly because of improved quality and higher frequency of neuroimaging for nonspecific symptoms, such as headache and vertigo ${ }^{(3)}$. For these patients, two management opportunities exist: preventive aneurysm repair or observation with follow-up imaging.
\end{abstract}

Saccular intracranial aneurysms are localized enlargement lesions of the vasculature, most commonly sited at bifurcation points in the circle of Willis. Often they will stay asymptomatic during the life. Its common presentation is rupture that leads to subarachnoid hemorrhage (SAH) but had other presentation as ischemic stroke or compressive symptoms. Material and Methods: we recruited 16 patients with intracranial aneurysm that had presentations other than subarachnoid hemorrhage and was treated by endovascular intervention and evaluated clinically and

Results: the mean age of patients was $5.75 \pm 11.1$ ranging between $23-69$ years. 10 patients were females and 6 were males. 7 patients $(43.8 \%)$ were hypertensive which was the commonest risk factor in those patients. 6 patients $(37.5 \%)$ had ICA aneurysm. Conclusion: endovascular therapy of intracranial aneurysms is a safe and effective method of

\section{PATIENTS AND METHODS}

We recruited patients who were submitted to endovascular therapy for symptomatic and asymptomatic cerebral saccular aneurysms between august 2017 and august 2018. All the patients had satisfied the following: ruptured aneurysm (presented by cerebral hematoma or subdural hematoma) or unruptured presented by mass effect or accidentally discovered (> 5 $\mathrm{mm})$ in anterior circulation, posterior circulation aneurysm and aneurysm in patient with past or family history of subarachnoid hemorrhage.

\section{Ethical approval:}

Written consents were obtained from all patients before the procedures. The study was approved by Aswan University, Faculty of Medicine Ethical Committee. Ethical approval no: ASU 44-1-16

All patients experienced clinical assessment together with Modified Rankin Scale (mRS) and NIHSS score on admission and 3-6 months follow up after procedure, brain CT scan, cerebral CT angiography (CTA) or MR angiography (MRA) when necessary, and six vessel digital subtraction cerebral angiography (DSCA) followed by endovascular aneurysmal therapy. Clinical and radiological (3D MRA or DSCA) follow-up was done 3- 6 months after discharge. A "good" outcome was defined as a mRS score of 0-2 at discharge; a "poor" outcome was defined as a mRS score of 3-6 at discharge.

\section{Technique of intervention and peri-procedural management}

All procedures were done through femoral puncture. Six vessels DSCA was done for all patients. Once saccular cerebral aneurysm was recognized, complete assessment of its angiographic features was done using three-dimension angiography or twodimension angiography in different projections. Our angiographic assessment aimed to identify the aneurysm site, size, presence of daughter aneurysm arising from the main sac, and presence of branch arising from the aneurysm. Bleeding aneurysm was identified via the distribution of the blood in the CT scan, the distribution of the vasospasm, and aneurysmal shape (lobulated aneurysm or presence of daughter aneurysm).

Systemic heparinization was done once the endovascular therapy was decided. Then, selective catheterization of the target vessel (either the internal carotid or the vertebral artery) was done using $6 \mathrm{~F}$ guiding catheter. Using coaxial system, the pathway to the aneurysm was navigated and then the aneurysmal sac was selectively catheterized using micro-catheter and treating it with optimum endovascular method either simple coiling, remodeling technique or flow diversion. Successful procedural outcome was well-defined as the target aneurysm having complete angiographic occlusion Classification (MRRC) into; class I (complete or residual neck according to Modified Ray- Mond-Roy 
obliteration), class II (residual neck), class IIIa (residual aneurysm with contrast within coil interstices), and class IIIb (residual aneurysm with contrast along aneurysm wall) in angiographic appearances. During follow-up, recurrence was defined as recanalization of a volume within the aneurysm large that need to retreatment with endovascular means $\mathbf{4}^{4}$.

\section{Statistical Analysis}

Patients' data, aneurysm features and therapeutic outcomes were tested as qualitative or continuous variables, as appropriate. Qualitative data are expressed as numbers and/or percentages. Mean values are presented as the mean \pm SD and the range. All data were analyzed with the aid of the SPSS version 16. The results were expressed as mean \pm SD. Spearman correlations between base line scores were also performed. Statistical analysis of the scores in each test was performed with repeated measures analysis of variance (ANOVA) with Time, as the within-subject factor. Greenhouse-Geisser degree of freedom corrections were applied to correct for the nonsphericity of the data. $P<.05$ was considered significant for all statistical analysis.

\section{RESULTS}

Table 1: patients' characteristics and initial clinical evaluation

\begin{tabular}{|c|c|c|c|}
\hline \multicolumn{2}{|l|}{ Patients character } & $n=16$ & $\%$ \\
\hline \multirow{2}{*}{\multicolumn{2}{|c|}{$\begin{array}{ll}\text { Sex } & \text { male } \\
& \text { Female }\end{array}$}} & 10 & 62.5 \\
\hline & & 6 & 37.5 \\
\hline Age per years & $\pm \mathrm{SD}$ & $\begin{array}{l}23-69 \\
51.75 \pm 11.1\end{array}$ & \\
\hline \multirow{3}{*}{ Risk factors } & hypertension & 7 & 43.8 \\
\hline & Diabetes mellitus & 4 & 25.0 \\
\hline & Undefined & 5 & 31.2 \\
\hline \multirow{6}{*}{ Clinical presentation } & headache & 1 & 6.2 \\
\hline & Confusion & 1 & 6.2 \\
\hline & Motor deficit & 4 & 25.0 \\
\hline & $3^{\text {rd }}$ nerve palsy & 4 & 25.0 \\
\hline & Asymptomatic & 4 & 25.0 \\
\hline & Multiple presentation & 2 & 12.5 \\
\hline \multicolumn{4}{|c|}{ Initial CT or MRI finding } \\
\hline & cerebral hematoma & 3 & 18.8 \\
\hline & Isodense mass lesion & 6 & 37.5 \\
\hline & Free imaging & 6 & 37.5 \\
\hline & Subdural hematoma & 1 & 6.2 \\
\hline
\end{tabular}

Table 2: angiographic assessment

\begin{tabular}{|ll|l|l|}
\hline & & $\mathrm{n}=16$ & \multicolumn{1}{|c|}{$\%$} \\
\hline Site & cavernous, ophthalmic & 6 & 37.5 \\
& MCA & 4 & 25 \\
& A.com & 2 & 12.5 \\
P.com & 2 & 12.5 \\
ICA bifurcation & 1 & 6.2 \\
Basilar & 1 & 6.2 \\
\hline Size & $<5 \mathrm{~mm}$ & 4 & 25 \\
& $>5 \mathrm{~mm}<10 \mathrm{~mm}$ & 3 & 56.2 \\
& $>10 \mathrm{~mm}$ & 18.8 \\
\hline
\end{tabular}




\begin{tabular}{|l|l|l|}
\hline Ruptured aneurysm & 4 & 25 \\
Unruptured aneurysm & 12 & 75 \\
\hline
\end{tabular}

Table 3: procedure out come

\begin{tabular}{|c|l|l|}
\hline & $\mathrm{n}=16$ & \multicolumn{2}{|c|}{$\%$} \\
\hline Procedure of treatment & 10 & 62.5 \\
Simple coiling & 1 & 6.2 \\
Balloon assisted coiling & 5 & 31.3 \\
\hline Flow diversion stent & & \\
Complication & 14 & 87.5 \\
No complication & 1 & 6.2 \\
Thrombus formation and vasospasm & 1 & 6.2 \\
Hydrocephalus & & \\
\hline Clinical out come & 11 & 68.8 \\
Improved & 4 & 25.0 \\
Not improved & 1 & 6.2 \\
Died & $\mathrm{n}=15$ & \\
Follow up angiography & 14 & 93.3 \\
Totally occluded & 1 & 6.7 \\
Recanalized & & \\
\hline
\end{tabular}

\section{DISCUSSION}

The prevalence of intracranial aneurysms (IA) accounts for 5\% in the general population, mostly intracranial aneurysms do not rupture over time, but the risk is size dependent. In the International study of unruptured intracranial aneurysms, the 5-year cumulative risk of rupture was negligible for those measuring $<7 \mathrm{~mm}$. Whereas the risk was $2.6 \%$ and $14.5 \%$ for those sized $7-12 \mathrm{~mm}$, located in the anterior and posterior circulation, respectively. Higher risk for rupture were found with larger sizes ${ }^{5}$.

Subarachnoid hemorrhage (SAH) due to a ruptured IA represents one of horrible diseases neurologists and neurosurgeons encounter in their practices. The yearly rate of SAH is approximately six to eight per 100,000 or about $25,000-27,000$ SAH cases a year in the United States ${ }^{6}$. Since the results of the International Subarachnoid Aneurysm Trial (ISAT) were published in 2002, endovascular treatment became a main treatment choice in the management of ruptured intracranial aneurysms ${ }^{7}$.

After the International Subarachnoid Aneurysm Trial (ISAT), endovascular coiling became the first treatment choice in many countries. The ISAT trial showed that coiling was associated with $7.4 \%$ absolute risk reduction at the outset and significantly fewer dead and dependent patients at 1 year than did clipping. After 10 years follow-up, although the rates of increased dependency did not change between both groups, the possibility of death or dependency was meaningfully greater in the clipping group than in the coiling group. Rebleeding was more likely after coiling than after clipping.

The ISAT randomized only aneurysms considered treatable by both techniques, resulted in only $22 \%$ of patients presented with bleeding aneurysm being included in the study. This point causes criticism due to selection bias. Another point that should be considered in the ISAT that endovascular coiling was done by highly experienced radiologists, and therefore, results cannot be generalized to other operators?

The substantiation for treatment of unruptured IA was more complex and dependent mainly on the assessment of risk of future spontaneous rupture (between $0.05 \%$ and $3.2 \%$ per year for aneurysms less than $10 \mathrm{~mm}$ and up to $5.5 \%$ per year for large aneurysms) 10,11 compared with the risks and efficacy of treatment. In the International Study of Unruptured Intracranial Aneurysm, endovascular morbidity and mortality ranged from $7.1 \%$ to $9.8 \%$, whereas surgical morbidity and mortality ranged from $10.1 \%$ to $12.6 \%{ }^{12-15}$.

In our study, 16 patients with intracranial aneurysms were treated with complete endovascular occlusion, their age ranged from 23 to 69 years with a mean age 51.75 years. The higher incidence of females $10(62.5 \%)$ than males $6(37.5 \%)$ males. Our results were consistent with other studies. In study of safety and efficacy of endovascular treatment of intracranial aneurysms by coiling with and without stent assistance in 235 cases, $180(76.5 \%)$ were female and $55(23.5 \%)$ were male with patient age ranged between 15 and 86 years, with a mean of 55 years. ${ }^{16}$ Hypertension was the commonest risk factor among our patients as 7 patients (43.7\%) were hypertensive. This result agreed with other study found that hypertension was the most prevalent risk factor 13 patients $41.9 \%{ }^{17}$.

In the current study, the angiographic outcome showed complete obliteration in 14 aneurysms (93.3\%), recanalization in one aneurysms $(6.7 \%)$. The immediate angiographic result of the (AMERICA) study showed that 52/100 aneurysms had complete occlusion, and 33/ 100 aneurysms had residual neck and 15/100 aneurysms residual sac ${ }^{\mathbf{1 8}}$.

\section{CONCLUSION}


Intracranial ruptured and unruptured aneurysms can be successfully treated with Interventional Neurology endovascular embolization technique, and with low risk of morbidity and mortality comparable with those described in previous studies.

\section{REFERENCES}

1-Qureshi AI, Suarez JI, Parekh PD et al. (1998): Risk factors for multiple intracranial aneurysms. Neurosurgery,43(1):22-6.

2-Rinkel GJ, Algra A (2011): Long-term outcomes of patients with aneurysmal subarachnoid haemorrhage. The Lancet Neurology, 10(4):349-56.

3- Gabriel RA, Kim H, Sidney S et al. (2010): Ten year detection rate of brain arteriovenous malformations in a large, multiethnic, defined population. Stroke, 41:21-26.

4. Mascitelli JR, Moyle H, Oermann EK et al.(2015): An update to the Raymond-RoyOcclusionClassification of intracranial aneurysms treated with coil embolization. J Neurointerv Surg., 7(7):496-502.

5-Connolly Jr ES, Rabinstein AA, Carhuapoma JR et al. (2012): Guidelines for the management of aneurysmal subarachnoid hemorrhage: a guideline for healthcare professionals from the American Heart Association/American Stroke Association. Stroke,43(6):1711-37.

6-Seibert B, Tummala R, Chow R (2011): Intracranial aneurysms: review of current treatment options and outcomes. Frontiers in neurology, 2:45.

7-Molyneux AJ, Kerr RS, Birks J et al. (2009): Risk of recurrent subarachnoid hemorrhage, death, or dependence and standardized mortality ratios after clipping or coiling of an intracranial aneurysm in the International Subarachnoid Aneurysm Trial (ISAT): long-term follow-up. The Lancet Neurology,8(5):427-33.

8-Molyneux A, Kerr R (2002): International Subarachnoid Aneurysm Trial (ISAT) Collaborative Group. International Subarachnoid Aneurysm Trial (ISAT) of neurosurgical clipping versus endovascular coiling in 2143 patients with ruptured intracranial aneurysms: a randomized trial. Journal of stroke and cerebrovascular diseases ,11(6):304-14.

9-Cognard C, Pierot L, Anxionnat R et al. (2011): Results of embolization used as the first treatment choice in a consecutive non selected population of ruptured aneurysms: clinical results of the Clarity GDC study. Neurosurgery, 69(4): 837-42.

10. Krings T, Mandell DM, Tim-Rasmus $\mathrm{K}$ (2011):Intracranial aneurysms: from vessel wall pathology to the therapeutic approach. Nat Rev Neurology,7:547-59.

11. Brisman JL, Song JK, Newell D (2006): Cerebral aneurysms. NEJM .,355:928-39.

12. Schievink WI, Schaid DJ, Michels V (1995): Familial aneurysmal subarachnoid hemorrhage: a community-based study. J Neurosurgery ,83:426-9

13. Minn R, Wiebers D, Whisnant J (1998): Un-ruptured Intracranial aneurysms - risk of rupture and risks of surgical intervention. the International Study of Un-ruptured Intracranial Aneurysms. NEJM., 339:1725-33.

14. Johnston SC, Wilson CB, Halbach V (2000): Endovascular and surgical treatment of un-ruptured cerebral aneurysms: comparison of risks. Ann Neurology, 48:11 9.

15. Meyers PM, Schumacher HC, Higashida R (2010): Reporting standards for endovascular repair of saccular intracranial cerebral aneurysms. J Neuro- Intervention Surgery, 2:312-23.

16-Chalouhi N (2012): Treatment of small ruptured intracranial aneurysms: comparison of surgical and endovascular options. Journal of the American Heart Association, 1(4): $\mathrm{e} 02865$.

17-Elewa M (2018): Endovascular coiling for cerebral aneurysm: single-center experience in Egypt. The Egyptian journal of neurology, psychiatry and neurosurgery, 54(1):33.

18. Fargen KM, Blackburn S, Deshaies E et al. (2014): Final results of the multicenter, prospective axiom micro FX for endovascular repair of intracranial aneurysm study (AMERICA). J Neuro-intervention Surgery, 27(1):40-3. 